\title{
RESTING RESPIRATORY BEHAVIOR IN MINIMALLY INSTRUMENTED TOADS - EFFECTS OF VERY LONG APNEAS ON BLOOD GASES AND pH
}

\author{
COELHO, F. C. ${ }^{1}$ and SMATRESK, N. J. ${ }^{2}$ \\ ${ }^{1}$ Laboratório de Pesquisas em Microcirculação, Instituto de Biologia, Universidade do Estado do Rio de Janeiro, \\ Pav. Haroldo Lisboa da Cunha, Térreo, CEP 20550-013, Rio de Janeiro, RJ, Brazil \\ ${ }^{2}$ Department of Biology, The University of Texas at Arlington, Box 19498, Arlington, Texas, 76019-0498, USA, \\ e-mail: smatresk@uta.edu \\ Correspondence to: Flávio Codeço Coelho, Laboratório de Pesquisas em Microcirculação, Instituto de Biologia, \\ Universidade do Estado do Rio de Janeiro, Pav. Haroldo Lisboa da Cunha, Térreo, CEP 20550-013, Rio de Janeiro, \\ RJ, Brazil, e-mail: fccoelho@uerj.br
}

Received March 1, 2002 - Accepted July 3, 2002 - Distributed February 28, 2003

(With 5 figures)

\begin{abstract}
Resting respiratory behavior of Bufo marinus in minimally instrumented toads is described for a period of 24 hours in which the animals are left undisturbed. Torpor-related long apneas are described and their implications for blood gas levels are investigated. Results show that the resting ventilation rate of Bufo marinus is much lower than that reported so far. Levels of arterial oxygen, carbon dioxide, and $\mathrm{pH}$ are monitored during artificial long apneas induced by anesthesia. The toads showed an unexpected ability to unload carbon dioxide by non-respiratory means, even while being kept on dry plastic box with no access to water. Oxygen arterial partial pressure dropped to very low levels after one hour of apnea. This suggests that these animals may endure very well severe hypoxia for long periods of time while in torpor.
\end{abstract}

Key words: amphibian, Bufo marinus, respiratory physiology, apnea, episodic breathing.

\section{RESUMO}

\section{Comportamento respiratório em repouso de sapos minimamente implantados - efeitos de apnéias de longa duração sobre o pH e gases sanguíneos}

O comportamento respiratório em repouso de Bufo marinus é descrito em animais minimamente implantados por um período de 24 horas, durante as quais os animais permanecem em total isolamento. Um estado de torpor associado a longas apnéias é descrito, e suas implicações sobre os níveis de gases sanguíneos é investigada. Os resultados mostram que o ritmo ventilatório em repouso de Bufo marinus é muito mais baixo do que o relatado na literatura até o presente. Os níveis arteriais de oxigênio, dióxido de carbono e pH foram monitorados durante longas apnéias induzidas artificialmente por meio de anestesia. Os sapos demonstraram capacidade surpreendente de eliminar dióxido de carbono por meios não respiratórios mesmo estando confinados em uma caixa plástica seca sem acesso a água. A pressão parcial de oxigênio arterial caiu a níveis extremamente baixos após uma hora de apnéia. Esses resultados sugerem que esses animais podem suportar muito bem hipoxia severa por longos períodos durante o estado de torpor.

Palavras-chave: anfíbio, Bufo marinus, fisiologia respiratória, apnéia, respiração episódica. 


\section{INTRODUCTION}

Anurans, with their episodic breathing pattern, display a remarkable flexibility in their respiratory behavior. The evolution of such flexibility most likely took place in close association with other behaviors (aestivation, diving, hibernation, etc.) that would benefit from this high level of control over ventilation.

The effects of episodic breathing on blood gas homeostasis have been studied in recent years (Burggren et al., 1989; Kinkead, 1997). However, those were acute experiments and could not reveal the long-term patterns associated with episodic breathing in a minimally instrumented resting animal.

In this study, ventilatory behavior was investigated by continuous lyrecording buccal pressure variations for a period of 24 hours. The animals were minimally outfitted (only a buccal catheter) and left undisturbed so that their "resting" ventilatory behavior could be observed. This also revealed the timescale of naturally occurring apneas, which were then tested as a possible source of large blood gas variations. Although short-term experiments on Bufo respiration in response to different respiratory challenges (hypoxia, hypercapnia, etc.) abound in the literature (Branco et al., 1991; Ishii, 1985; Macintyre \& Toews, 1976; Smatresk \& Smits, 1991; Van Vliet \& West, 1992), a description of Bufo's resting respiratory behavior (with minimally instrumented animals) was still lacking.

The effects of prolonged apneas are easy to model from what is known of amphibian respiratory physiology: blood oxygen content should decrease exponentially while $\mathrm{CO}_{2}$ increases, leading to a slight acidosis. This is in accordance with the conclusions of Shelton \& Boutilier (1982). To test these hypotheses about changes in blood gas tensions during a long, voluntary apnea in Bufo marinus, an experiment was set up with anestheticinduced apneas. The toad was anesthetized until it stopped breathing and was kept under anesthesia for one hour. Oxygen, $\mathrm{CO}_{2}$, and $\mathrm{pH}$ levels in arterial blood were monitored throughout that hour at controlled intervals.

Amphibians are reasonably efficient cutaneous exchangers of gases and ions due to their highly vascularized and glandular epithelium (Feder, 1988; Pinder \& Feder, 1990; Powell \&
Hempleman, 1993; Toews \& Stiffler, 1990). Cutaneous perfusion and glandular secretions are also actively controlled to meet environmental demands for gas exchange and osmoregulation. Cutaneous exchange works well for unloading $\mathrm{CO}_{2}$ but is not very effective for oxygen uptake due to its lower solubility in blood and tissue fluids. Thus, we can expect to see a continuous fall in arterial oxygen levels.

Bufo marinus has also been shown to possess other mechanisms to compensate for high $\mathrm{CO}_{2}$ levels in the blood, one example being the mobilization of $\left[\mathrm{HCO}_{3}^{-}\right]$reserves from $\mathrm{CaCO}_{3}$ crystals in endolymphatic sacs (Toews \& Stiffler, 1990).

A detailed description of the dynamics of blood gas tensions during the long apneas naturally displayed by Bufo will lead to a better understanding of the species' respiratory capabilities and how they can serve as an adaptive advantage to the animal.

\section{MATERIALS AND METHODS}

The study was conducted in two phases. In the first, a group of undisturbed toads was monitored continuously for 24 hours to determine baseline resting ventilatory behavior as well as the size of naturally occurring apneas. In the second phase a different group of toads was surgically implanted with buccal and arterial catheters and anesthetized to simulate torpor-related apneas.

\section{Resting ventilatory behavior: 24-hour runs}

Ten toads (180 to $285 \mathrm{~g}$ ) were selected randomly from a larger group of animals kept in the lab under the same temperature $\left(23^{\circ} \mathrm{C}\right)$, lighting (12/12, light/dark), and feeding conditions (toads were fed crickets - Acheta domestica - every three days). Toads were fastened for $72 \mathrm{~h}$ before undergoing the experimental procedures. They were anesthetized with MS-222 (Argent chemical laboratories) and implanted with an air-filled buccal catheter (PE-205, Intramedic) inserted through the right tympanic membrane. Each animal was then transferred to a clean plastic box filled with $2 \mathrm{~cm}$ of water and allowed 24 hours to recover from surgery. On the next day, the toad was transferred to a dry plastic cage that was continuously ventilated with fresh ambient air, and its buccal catheter was connected to a pressure transducer 
(Validyne DP-45). The bottom of the cage was covered with two or three sheets of moistened paper towels. One hour later, digitizing (50 samples/ second, 12-bit A/D conversion) and recording of buccal pressure began through a computerized data acquisition system (Windaq 220, Dataq instruments). The 12/12 light/dark cycle was maintained throughout the experiment with the light period starting at 8:00 A.M. The experiments were started at random times during the day and lasted 24 hours.

A peak detection algorithm from Windaq Waveform Browser software (Dataq Instruments) was used to identify respiratory breaths in the 24hour recordings of buccal pressure. Spuriously marked peaks (non-respiratory buccal oscillations, NRBOs) were identified by visual inspection and unmarked. The amplitude of the marked peaks and interbreath intervals were determined and recorded together with their position in time.

From this data, we calculated a variety of statistical descriptors based on ventilatory parameters (Fig. 1): mean buccal pulse amplitude - BPA
$\left(\mathrm{cmH}_{2} \mathrm{O}\right)$ : average amplitude of all respiratory buccal pulses; breathing frequency $-\mathrm{F}_{\mathrm{b}}$ (breaths. $\min ^{-1}$ ): based on the average of all interbreath intervals; longest apnea (h): single longest interval between any two breaths; interbout interval - IboI (s): average of interbreath intervals (IBI) longer than 2 seconds and shorter than one hour. Intervals shorter than 2 seconds include the intervals between breaths within a bout; very large intervals (more than 1 hour long) are qualitatively different from regular interbout intervals. When an animal displays very long apneas it is in an apparently dormant state instead of awake and engaged in active ventilatory behavior. In this study, the term interbreath interval is used in the broad sense of any interval between respiratory breaths. An interbout interval will be the time period separating a breathing bout, and the next breath (that is not part of the same bout) or breathing bout. The definition of a bout used here was of a continuous sequence of at least two breaths (with no NRBO between them).

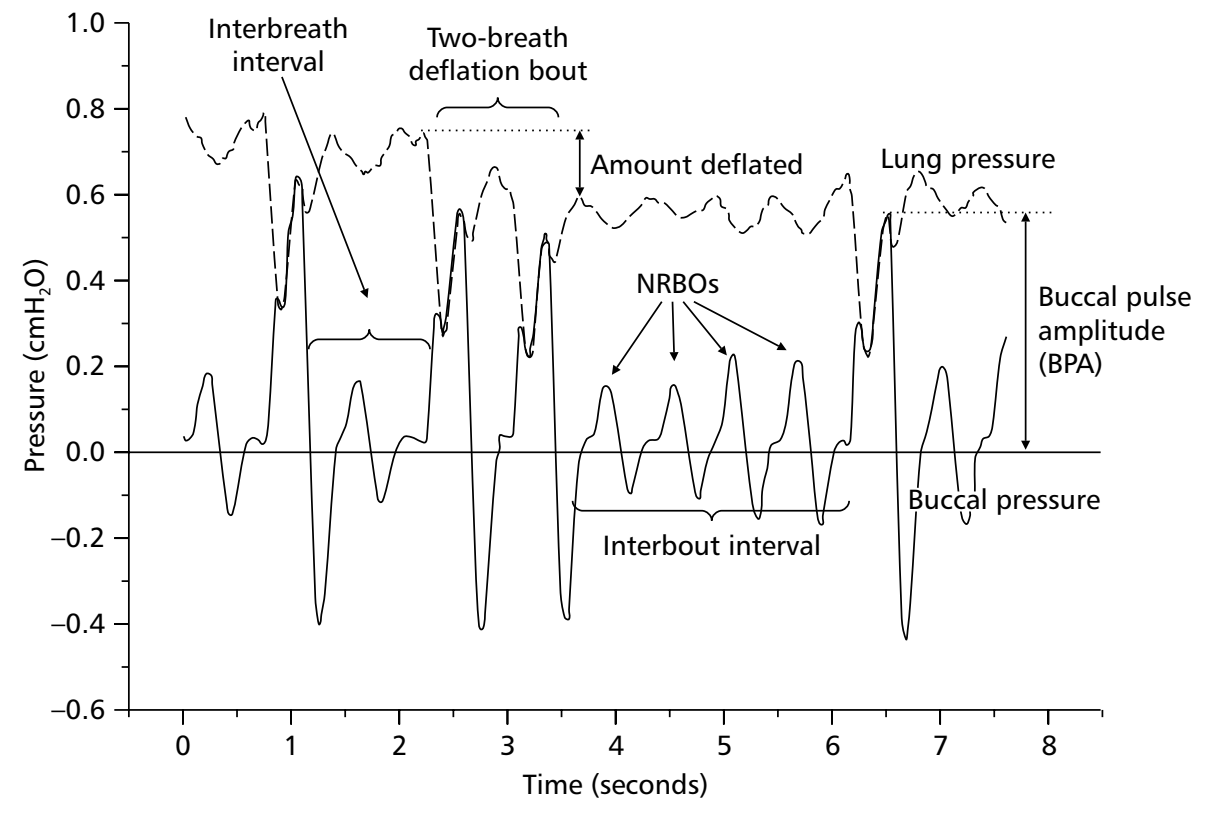

Fig. 1 - Sample trace illustrating the parameters extracted from the toad's respiratory variables. Lung pressure is shown for reference but was not recorded during these experiments. Other features of the respiratory trace are also illustrated, such as a breathing bout and NRBOs. Note that respiratory breaths can be easily (visually) told apart from non-respiratory ones. 


\section{Blood gas levels in urethane-induced apneas}

Seven large toads (307-454 grams) were selected from the same population described above. Larger toads were chosen to facilitate the arterial catheter implantation. Toads were anesthetized, as mentioned before, and implanted (occlusive cannulation) with a heparinized polyethylene catheter (PE-50, Intramedic) in the sciatic artery of the right leg, which did not prevent the toad from assuming a normal posture after recovering from anesthesia.

A buccal catheter was also implanted as described above to monitor respiratory activity. The animal was allowed 24 hours to recover from the surgery.

On the next day, shortly before the start of the experiment, the arterial catheter was connected, via a 2 -way stopcock, to a $1 \mathrm{ml}$ syringe used to administer the anesthetic urethane and obtain the blood samples.

After the 24-hour recovery period, the animal was placed in a dry plastic cage. A $0.7 \mathrm{ml}$ blood sample was taken and analyzed immediately before administration of $3 \mathrm{ml}$ of $15 \%$ urethane (Ethyl carbamate, Sigma) in amphibian (Cortland) saline (Coelho, 1999) via the arterial catheter. Within a minute of injection all animals stopped breathing and $0.7 \mathrm{ml}$ blood samples were taken at 5, 15, 30, and 60 minutes after beginning of the apneic period. Immediately after removal of each blood sample, $0.7 \mathrm{ml}$ of Cortland saline was injected to maintain blood volume. An extra $1 \mathrm{ml}$ of the $15 \%$ urethane solution was given after 30 minutes to insure the animal would not take a breath before 60 minutes of apnea. Blood samples were analyzed for $\mathrm{PO}_{2}, \mathrm{pH}$ (Cameron Blood Gas Meter-BGM200), and total $\mathrm{CO}_{2}$ (Cameron Capnicon 5). Hematocrits were carefully monitored for each sample to check for significant anemia that could be caused by serial removal of blood samples. Respiratory activity was monitored (via buccal catheter) throughout the experiment to confirm the apneic state.

Regression analysis was used to test for variations in blood gases and $\mathrm{pH}$ during the urethane induced apneas.

\section{RESULTS}

The resting ventilatory behavior of Bufo, recorded in the 24-hour trials, revealed results that are in clear contrast to those reported in existing literature on the topic. Overall breathing frequency was typically 1 to 2 breaths per minute, which is much lower than previously published values. (Table 1 shows average values for each animal.) Shelton \& Boutilier (1982) reported 31 breaths/ min for Bufo, and Boutilier (Boutilier \& Toews, 1977 ) reports $16 \pm 1.38$ breaths $/ \mathrm{min}$. This dramatically low breathing frequency resulted from shorter breathing bouts of (i.e., fewer breaths per bout than typically observed) and relatively long apneas. Apneas could be further characterized as short apneas, occurring while animals were in a normally active state, and very long apneas (0.67$8.4 \mathrm{~h})$, in which toads appeared to be in a torpid state.

Buccal pulse amplitudes, on the other hand, did not seem to vary substancially from the values observed previously on more instrumented animals (Coelho et al., 1997). The Fig. 2 shows a 14-hour segment of a 24-hour recording (highly compressed) of buccal pressure from a typical animal. Despite the high compression, it is still possible to recognize apneas, lung inflation breaths (consisting of a crescendo of buccal pressure oscillations), and non-respiratory buccal oscillations (smaller peaks between lung inflation bouts). In this trace the animal displays 2 apneas that are about 1 hour long, and a 2-hour apnea. Table 1 lists the parameters extracted from buccal pressure recordings.

Mean buccal pulse amplitude (BPA) did not vary much among animals (Table 1). However, the amplitude of individual pulses displayed considerable variation within each toad. This is due to the use by the toad of buccal pulses of various sizes to regulate inflation level of its lungs. No significant correlation was found between body mass and either BPA $(\mathrm{R}=-0.41 ; \mathrm{p}=0.18)$, breathing frequency $\left(f_{b}\right)(R=0.43 ; p=0.24)$, or interbout interval $(\mathrm{R}=0.33 ; \mathrm{p}=0.39)$. The fact that all toads display a very similar value for BPA despite different sizes may reflect the range of pressure that toad lungs can withstand.

The Fig. 3 shows a typical record of the full 24 hours of data demonstrating both buccal pulse amplitude and distribution of each respiratory breath over time. When reviewing these traces for all the animals, it was readily apparent that the animals did not display any obvious circadian pattern in their respiratory behavior. 
TABLE 1

Basic statistics describing the ventilatory behavior of undisturbed toads in a 24-hour period. Each line corresponds to 1 animal. * This column refers to the intervals used to calculate the average interbout intervals.

\begin{tabular}{|c|c|c|c|c|c|c|}
\hline $\begin{array}{c}\text { Buccal pulse } \\
\text { amplitude } \\
(\text { cmH } \\
\bar{X} \pm S D\end{array}$ & $\begin{array}{c}\text { Breathing } \\
\text { frequency }\left(\mathrm{min}^{-1}\right) \\
\bar{X} \pm S D\end{array}$ & $\begin{array}{c}\text { Longest } \\
\text { apnea } \\
\text { (h) }\end{array}$ & $\begin{array}{c}\text { Body } \\
\operatorname{mass}(\mathrm{g})\end{array}$ & $\begin{array}{c}\text { Number of } \\
\text { breaths } \\
\text { averaged }\end{array}$ & $\begin{array}{c}\text { Interbout } \\
\text { interval (sec) } \\
(\bar{X} \pm S E)\end{array}$ & $\begin{array}{c}\text { Number of } \\
\text { intervals } \\
\text { averaged* }\end{array}$ \\
\hline $1.4 \pm 0.7$ & $1.67 \pm 0.09$ & 8.4 & 203 & 2401 & $21.1 \pm 2.9$ & 2398 \\
\hline $1.9 \pm 0.9$ & $2.05 \pm 0.18$ & 3.3 & 194 & 2709 & $17.4 \pm 1.8$ & 2703 \\
\hline $1.0 \pm 0.8$ & $13.9 \pm 1.26$ & 1.5 & 208 & 20066 & $19.6 \pm 1.05$ & 3550 \\
\hline $1.7 \pm 1.3$ & $0.59 \pm 0.07$ & 5 & 237 & 514 & $86.7 \pm 11.6$ & 384 \\
\hline $1.9 \pm 1.8$ & $0.88 \pm 0.27$ & 0.67 & 215 & 760 & $97 \pm 11$ & 528 \\
\hline $1.0 \pm 0.6$ & $1.92 \pm 0.28$ & 2.16 & 285 & 2767 & $40.1 \pm 3.9$ & 1933 \\
\hline $1.6 \pm 0.9$ & $0.09 \pm 0.04$ & 3.1 & 180 & 141 & $508.3 \pm 102.6$ & 77 \\
\hline $1.0 \pm 0.8$ & $0.84 \pm 0.15$ & 2.68 & 194 & 1221 & $64.8 \pm 6.2$ & 1016 \\
\hline $1.7 \pm 1.4$ & $0.78 \pm 0.21$ & 0.95 & 205 & 1123 & $180.9 \pm 18.84$ & 471 \\
\hline
\end{tabular}

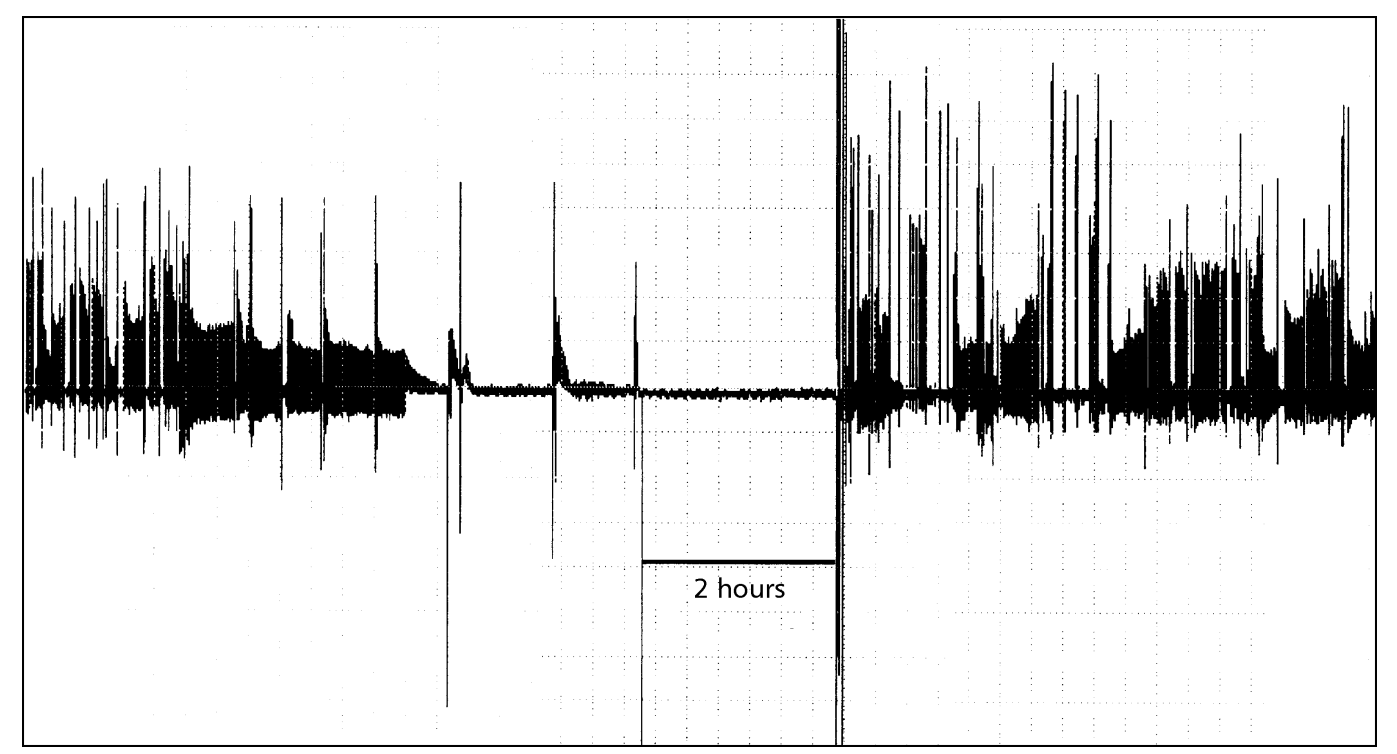

Fig. 2 - Compressed buccal pressure traces of part of a $24 \mathrm{~h}$ run. Y-axis is pressure. 


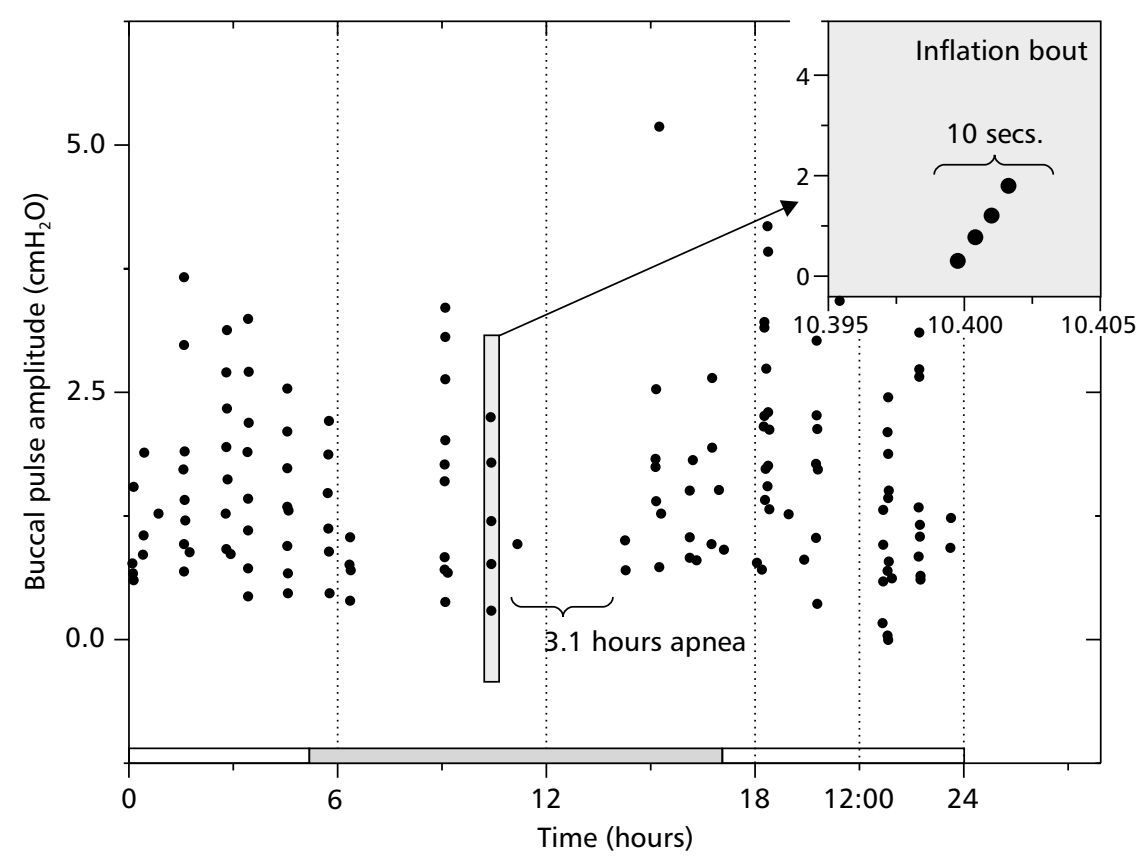

Fig. 3 - This plot shows the actual distribution of respiratory breaths over 24 hours. Each dot is a breath and the Y-axis gives the intensity of the buccal pulse in $\mathrm{cmH}_{2} \mathrm{O}$. The "12:00" indicates mid-day relative to the experiment. The inset zooms in on a breathing bout so as to reveal its actual structure on a more expanded time scale.

Similarly, no changes in respiratory behavior were apparent whether the lights were on or off. The white and shaded bars in the bottom of the graph represent the light and dark periods for this particular run.

The periods of more intense breathing activity seemed to distribute themselves irrespective of the light/dark cycle. Since the animals were undisturbed during the run, external influences cannot be associated with periods of more intense breathing. In this figure, the time scale is very compressed and breathing bouts appear as a series of dots one on top of the other. The inset zooms in on a breathing bout to reveal the actual structure of a lung inflation cycle with a more expanded time scale.

Urethane induced apneas strongly affected arterial oxygen levels but not total $\mathrm{CO}_{2}$ content. Arterial $\mathrm{pH}$ did not show any indication of respiratory acidosis but in the last 30 minutes of apnea there was a significant $\mathrm{pH}$ drop, possibly due to metabolic acidosis. During the 1-hour long urethane induced apnea, arterial $\mathrm{PO}_{2}\left(\mathrm{P}_{\mathrm{a}} \mathrm{O}_{2}\right)$ fell exponentially (Fig. 4) from $80-125 \mathrm{mmHg}$ (before the apnea), reaching the 10-20 $\mathrm{mmHg}$ range after one hour without breathing. An exponential decay model fitted the data well (Fig. 4, Table 2) $(\mathrm{R}=0.92$; explained variance $=84.3 \%$ ).

Such a good fit provides strong support for a constant rate of $\mathrm{O}_{2}$ consumption by the toads during the 1-hour long apnea.

$\mathrm{TCO}_{2}$ displayed a statistically insignificant $(\mathrm{R}=-0.34, \mathrm{p}=0.09)$ drop during the 1-hour apneic period (Fig. 5). Arterial $\mathrm{pH}$ fell significantly during the same period $(\mathrm{R}=-0.58 ; \mathrm{p}=0.0014)$. This acidification was entirely due to the $\mathrm{pH}$ fall in the last 30 minutes, since during the first half of the apnea it remained virtually unchanged.

Hematocrit for all animals was significantly higher $(p=0.007)$ after 60 minutes of apnea, suggesting no oversampling. 


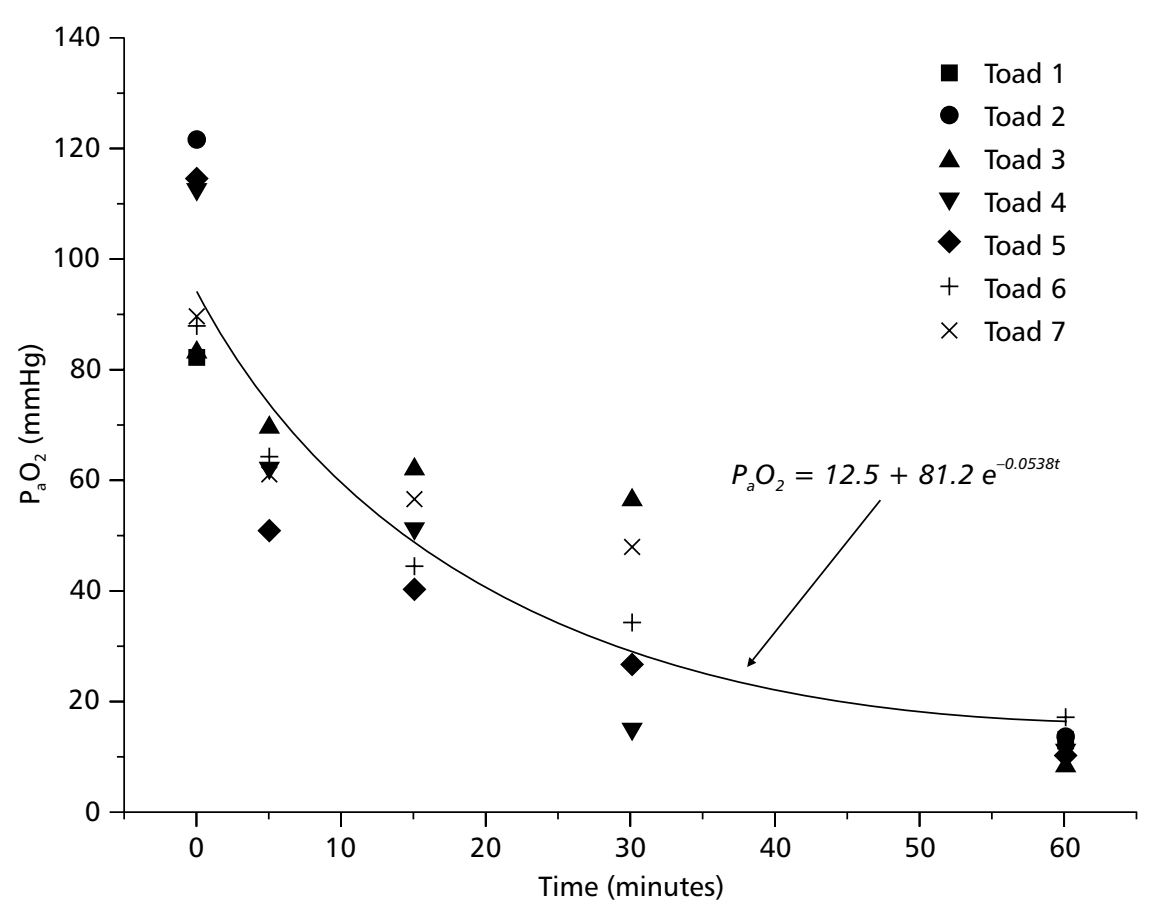

Fig. 4- Oxygen levels in arterial blood during a long apnea. Curve represents the exponential decay equation (shown above it) fitted to the data.

TABLE 2

Parameters adjusted for the first-order exponential decay model fit to $\mathrm{P}_{\mathrm{a}} \mathrm{O}_{2}$ data.

Equation: $P_{a} O_{2}=y 0 a l \cdot e^{-(t-t 0) / t 1}$

\begin{tabular}{|l|c|c|}
\hline \multicolumn{1}{|c|}{ Parameters } & Value & Error \\
\hline y0 (vertifcal offset) & 12.55 & \pm 7.69 \\
\hline t0 (horizontal offset) & 0 & \pm 0 \\
\hline a1 (amplitude) & 81.13 & \pm 8.15 \\
\hline t1 (decay constant) & 18.60 & \pm 5.14 \\
\hline
\end{tabular}




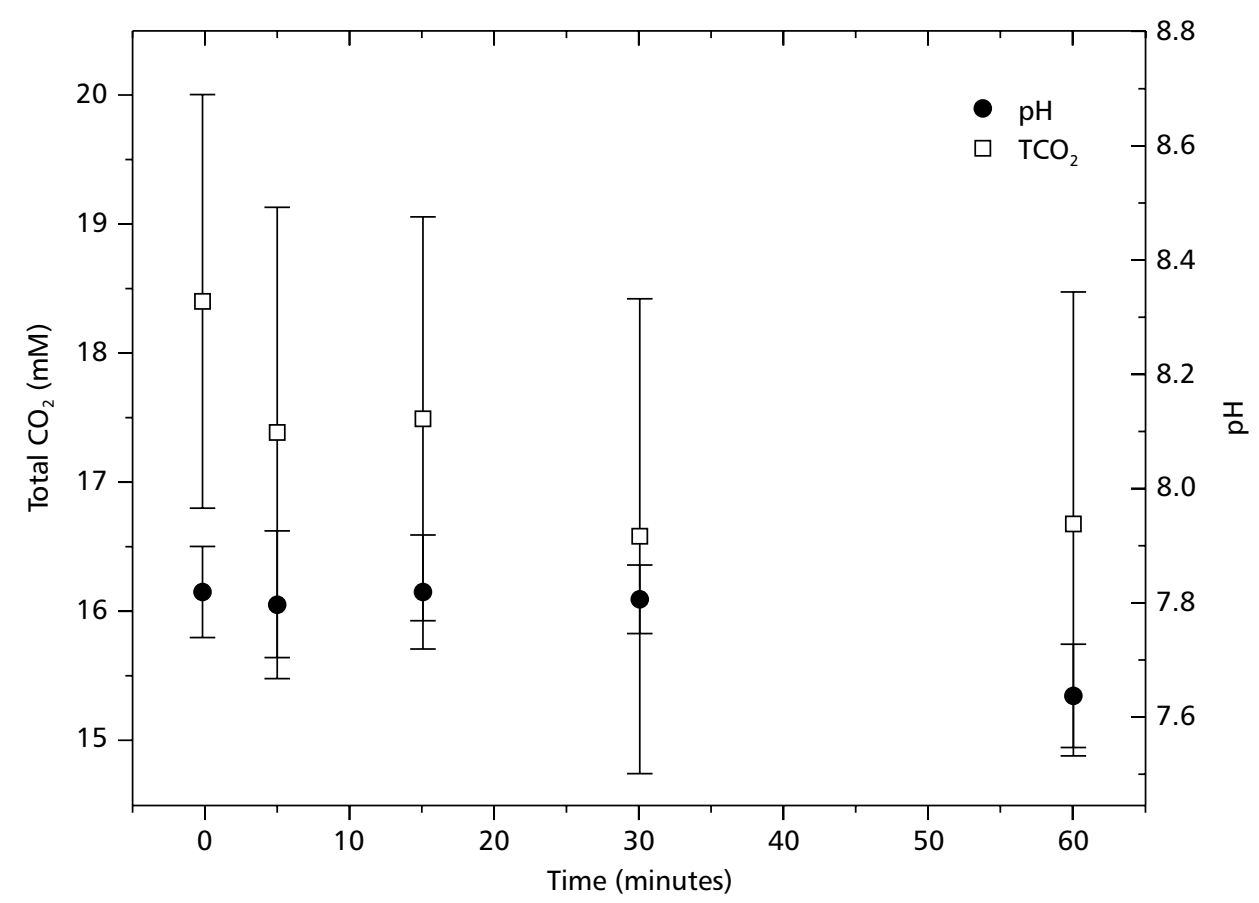

Fig. 5 - Total carbon dioxide content $(\mathrm{mM})$ and $\mathrm{pH}$ of arterial blood during a long apnea.

\section{DISCUSSION}

It has been demonstrated that arterial $\mathrm{PO}_{2}$ in diving amphibians and reptiles drops considerably even during short apneic periods (Shelton \& Boutilier, 1982). Bufo marinus, though not a diving animal, also undergoes voluntary apneas of considerable duration, as shown in Table 1. To the best of our knowledge, the longer apneas recorded in this study (up to 8 hours long) exceed any previously described for Bufo marinus respiratory behavior. While there is an abundance of published studies on apneas associated with diving, overwintering, aestivation, and other specific behaviors (Boutilier et al., 1979b; Boutilier et al., 1997; Burggren et al., 1989; Donohoe et al., 1998; Fishman et al., 1989; Shelton \& Boutilier, 1982; West \& Burggren, 1984; White et al., 1989), no previous study has dealt with naturally occurring apneas in undisturbed resting animals. The length of the apneas, in one case up to 8 hours, was startling, and far surpassed our expectations. This simple observation suggests that many poor assumptions have been made in previous studies concerning resting behavior, metabolism, and gas exchange in these routinely studied animals. Aside from the long apneas, this study shows that even when the toads were actively ventilating, the overall average breathing frequency of $2.52 \pm 1.43$ breaths/ minute $(\bar{X} \pm S E)$ in an undisturbed, minimally instrumented toad is much lower than indicated previously published data for resting toads: Boutilier \& Toews (1977) reported an average of $16.27 \pm 1.38$ breaths/ minute $(\bar{X} \pm S E)$ for resting toads implanted with both a buccal and an arterial catheter, i.e., about $700 \%$ higher than shows in the current study. Boutilier et al. (1979a), reported a resting rate of $13.4 \pm 1.6$ breaths/minute $(\bar{X} \pm \mathrm{SE})$ using a similar preparation. Boutilier et al. (1979b) reported an average breathing frequency of around 17 breaths/ minute (exact values not reported) for toads implanted with a buccal and an arterial catheter. Comparing these published reports with the values found in this study, it can be suggested that arterial catheterization is a highly "disturbing" 
procedure, and that there may be a positive correlation, possibly related to increased discomfort level, between surgical internation level and between and overall ventilation rate.

In animals implanted with arterial catheters in this study, apneas longer than 10 minutes were uncommon, and resting ventilation rates appeared to be significantly higher than in less instrumented toads (personal observations). Because of this, it was not possible to obtain a reasonable estimate of the blood gas change during prolonged apneas. Therefore, we resorted to an anesthetized experimental preparation. While it is clear that anesthetic might compromise blood gas exchange, hence tensions via alterations in either regulation of blood flow or metabolism, it provided the only available means for arriving oxygen disappearance and $\mathrm{CO}_{2}$ buildup estimates. Results from artificially induced apnea studies suggested that naturally occurring apneas must profoundly affect an animal's $\mathrm{P}_{\mathrm{a}} \mathrm{O}_{2}$ but to a much lesser extent its blood $\mathrm{CO}_{2}$ levels. Blood acid-base balance is also affected in the long run, as anaerobic metabolic pathways are activated after oxygen has fallen below a certain threshold. Shelton \& Boutilier (1982) report that the African clawed frog, Xenopus laevis, displays drops in $\mathrm{P}_{\mathrm{a}} \mathrm{O}_{2}$ similar to that found in this study. During a voluntary dive of about $30 \mathrm{~min}$ at $25^{\circ} \mathrm{C}, \mathrm{P}_{\mathrm{a}} \mathrm{O}_{2}$ droped from a range of $80-125 \mathrm{mmHg}$ (normal levels) down to $10-15$ $\mathrm{mmHg}$ at the end of the dive. These values are quite close to those shown in Fig. 4, but the same drop took about twice as long during artificially induced apneas in Bufo. This may be due to the fact that the toads in this study were anesthetized and not swimming under water, and thus had a lower metabolic rate. Anesthesia was likely to have had an overall depressing effect on the toad's metabolic rate. These results may be reasonably close estimates of the behavior of animals experiencing long apneas, since they appeared to be in a torpid state during the long apneas that may mimic the reduced metabolic rate of dormant animals in their burrows (Boutilier et al., 1979b).

During long naturally occurring apneas, toads may rely on cutaneous and/or buccopharyngeal gas exchange. Since the undisturbed toads in this study rarely displayed NRBOs during the very long apneic periods, cutaneous respiration is the most likely source of gas exchange. The transition to a dormant state may be due to the lack of any external sensory stimuli.

Boutilier et al. (1979a) report that Bufo marinus initiates burrowing within 1-2 hours of being left undisturbed in a sand-filled terrarium. However, in that study breathing frequency never reached values as low as the ones found in this, which may be because the burrowed toads never stopped breathing completely. If the behavior observed in this study is really a form of burrowing torpor, the air surrounding the skin, constantly stirred by the flow of air through the cage, might provide a better environment for cutaneous gas exchange than do burrow conditions, thus allowing for extremely low lung ventilation frequency.

Boutilier et al. (1979a) found that during burrowing a toad's arterial $\mathrm{PCO}_{2}$ doubles and arterial $\mathrm{PO}_{2}$ drops considerably (to about $60 \mathrm{mmHg}$ ). The data from the anesthetized, apneic toads indicate that either they are much more efficient in unloading $\mathrm{CO}_{2}$ when not burrowed, or have lower overall metabolism. However, oxygen levels can drop considerably lower which might indicate an ability to endure extreme hypoxia so far unsuspected for Bufo marinus. In the apnea experiment, all individuals recovered fully from the 1-hour urethane induced apnea, displaying normal ventilatory patterns shortly after recovering from anesthesia.

It is possible that for animals that do not go into a deep torpor (i.e., those that still display NRBOs during the apneas) buccopharyngeal gas exchange may prevent $\mathrm{P}_{\mathrm{a}} \mathrm{O}_{2}$ from dropping so much. Unfortunately, to verify this hypothesis a long-term experiment on a toad implanted with an arterial catheter would be necessary but such a toad would not display the long apneas characteristic of undisturbed and minimally instrumented toads.

By the end of the 1-hour apneic period arterial oxygen seems to reach a stable point at around $18 \mathrm{mmHg}$. This may be due to a shift to anaerobic metabolism or because oxygen uptake through the skin matches $\mathrm{VO}_{2}$ at this point

During the 1-hour long apneic period $\mathrm{T}_{\mathrm{a}} \mathrm{CO}_{2}$ did not increase significantly. It is known that amphibian skin is an important site for $\mathrm{CO}_{2}$ exchange due to the great solubility of this gas in water (Pinder \& Feder, 1990). Terrestrial amphibians like Bufo marinus, however, are not commonly thought of as being very good cutaneous exchangers due to 
their thick skin in combination with their terrestrial habits. Moreover, these experiments were not conducted in an aquatic environment. The method used for quantification of the total amount of carbon dioxide in the blood removes all the $\mathrm{CO}_{2}$ from the blood samples, both dissolved and in the form of $\mathrm{HCO}_{3^{-}}$(bicarbonate) ions. Thus, $\mathrm{CO}_{2}$ produced during the hour-long apnea is being shunted away from the blood in a way that could not be determined in the context of these experiments. The values found in the present study for total $\mathrm{CO}_{2}$ on a resting toad at $23^{\circ} \mathrm{C}$ (Fig. 5) are consistent with the resting values reported by Stinner et al. (1994). Stinner reports $19.7 \pm 1.8 \mathrm{mmol} / \mathrm{L}$ at $25^{\circ} \mathrm{C}$ and we have found $\mathrm{T}_{\mathrm{a}} \mathrm{CO}_{2}$ at $23^{\circ} \mathrm{C}$ to be $18.4 \pm-1.61 \mathrm{mmol} / \mathrm{L}$ with the animal at rest.

Toews (1990) suggestion that the urinary system (kidney and urinary bladder) is an important site for acid-base regulation in the marine toad does not seem to be the case here since it would involve an exchange of $\mathrm{CO}_{2}$ for bicarbonate ions $\left(\mathrm{HCO}_{3}^{-}\right)$. Stinner et al . (1994) demonstrated that intracellular fluid can store significant $\mathrm{CO}_{2}$ amounts with the skin being the most important site, storing $45 \pm 11.5$ mmoles of $\mathrm{CO}_{2}$ per kilogram at $26^{\circ} \mathrm{C}$. This amount is much more than the plasma total concentration of carbon dioxide $(19.7 \pm 1.8 \mathrm{mmol} / \mathrm{L})$. Thus, it is likely that $\mathrm{CO}_{2}$ is exchanged across the skin and/or stored in skin during the apneic period in the current study.

Despite the lack of significant accumulation of carbon dioxide in the toad's blood during the 1hour long apnea, $\mathrm{pH}$ dropped significantly in the last 30 minutes. This metabolic acidosis is likely the result of lactate accumulation from anaerobic metabolism. Shelton \& Boutilier (1982) report that during voluntary dives of approximately 30 minutes, there is very little change in lactate concentration in the blood of the African clawed frog Xenopus laevis. Unfortunately, lactate was not measured during this experiment, thus the extent of lactate accumulation and anaerobic metabolism could not be estimated.

\section{CONCLUSIONS}

The evidence gathered in this study calls for the reexamination of many facts previously believed true about Bufo marinus respiratory physiology and behavior. First of all the resting ventilatory behavior of this toad is much less intense than previously observed. This fact alone makes us think about very inadequate are the controls used in most respiratory studies on this species. In some experimental setups, the fact that the animals start off in a highly excited as compared to their natural resting state may limit the extent to which the organism may respond to further respiratory challenges. It may also affect the response qualitatively.

Another fact unveiled in this study is the remarkable ability of this species to unload $\mathrm{CO}_{2}$ from its arterial blood. The mechanisms used to eliminate this $\mathrm{CO}_{2}$, and its final destination, is a question open for future investigations. The extent of the ability of this species to withstand hypoxia for such long periods of time is interesting and calls for more study of the mechanisms involved.

Acknowledgments - We thank the anonymous referees for helpful comments which contributed to making the text more clear. This work was supported by the Brazilian Research Council (CNPq) and by NIH GrantR15HL48278.

\section{REFERENCES}

BOUTILIER, R. G., DONOHOE, P. H., TATTERSALL, G. J. \& WEST, T. G., 1997, Hypometabolic Homeostasis in overwintering aquatic amphibians. J. of Exp. Biol., 200 : $387-400$.

BOUTILIER, R. G., RANDALL, D. J., SHELTON, G. \& TOEWS, D. P., 1979a, Acid-base relationships in the blood of the toad, Bufo marinus III. The Effects of Burrowing. J. Exp. Biol., 82: 357-365.

BOUTILIER, R. G., RANDALL, D. J., SHELTON, G. \& TOEWS, D. P., 1979b, Acid-base relationships in the blood of the toad, Bufo marinus. I. The effects of environmental CO2. J. Exp. Biol., 82: 331-344.

BOUTILIER, R. G. \& TOEWS, D. P., 1977, The effect of progressive hypoxia on respiration in the toad Bufo marinus. J. Exp. Biol., 68: 99-107.

BRANCO, L. G. S., GLASS, M. L. \& HOFFMANN, A., 1991, Central chemoreceptor drive to breathing in unanesthetized toads, Bufo paracnemis. Respir. Physiol., 87: 195-204.

BURGGREN, W. W., SMITS, A. \& EVANS, B., 1989, Arterial $\mathrm{O}_{2}$ Homeostasis during Diving in the Turtle Chelodina longicollis. Physiol. Zool., 62: 668-686.

COELHO, F. C., BAKER, T. L. \& SMATRESK, N. J., 1997, Coherence and Wavelet Analysis of ventilatory time series in the toad, Bufo marinus, an episodic breather. The FASEB Journal, 11: A30.

COELHO, F. C., 1999, Afferent signal oscillations and the control of breathing in Bufo Marinus. Ph.D. Dissertation. The University of Texas at Arlington. 
DONOHOE, P. H., WEST, T. G. \& BOUTILIER, R. G., 1998, Respiratory, metabolic, and acid base correlates of aerobic metabolic rate reduction in overwintering frogs. Am. J. Physiol., 274: R704-R710.

FEDER, M. E., 1988, Exercising with and without lungs II. Experimental elimination of pulmonary and buccopharyngeal gas exchange in individual salamanders (Ambystoma tigrinum). J. Exp. Biol., 138: 487-497.

FISHMAN, A. P., GALANTE, R. \& PACK, A. I., 1989, Diving physiology. In: S. C. Wood (ed.), Comparative pulmonary physiology: current concepts. Marcell Dekker, Inc., New York.

ISHII, K., 1985, Chemo- and baro receptor innervation of the aortic trunk of the toad Bufo vulgaris. Respir. Physiol., 60: 365-375.

KINKEAD, R., 1997, Episodic breathing in frogs: Converging hypotheses on neural control of respiration in air breathing vertebrates. Amer. Zool., 37: 31-40.

MACINTYRE, D. H. \& TOEWS, D. P., 1976, The mechanics of lung ventilation and the effects of hypercapnia on respiration in Bufo marinus. Can. J. Zool., 54: 1364-1374.

PINDER, A. W. \& FEDER, M. E., 1990, Effect of Boundary layers on cutaneous gas exchange. J. Exp. Biol., 143: 6780.

POWELL, F. L. \& HEMPLEMAN, S. C., 1993, Difusion limitation in comparative models of gas exchange. Respir. Physiol., 91: 17-29.
SHELTON, G. \& BOUTILIER, R. G., 1982, Apnoea in amphibians and reptiles. J. Exp. Biol., 100: 245-273.

SMATRESK, N. J. \& SMITS, A. W., 1991, Effects of central and peripheral chemoreceptor stimulation on ventilation in the marine toad, Bufo marinus. Respir. Physiol., 83: 223-238.

STINNER, J. N., NEWLON, D. L. \& HEISLER, N., 1994, Extracellular and intracellular carbon dioxide concentration as a function of temperature in the toad Bufo marinus. J. Exp. Biol., 195: 345-360.

TOEWS, D. P. \& STIFFLER, D. F., 1990, Compensation of progressive hypercapnia in the toad (Bufo marinus) and the bullfrog (Rana catesbeiana). J. Exp. Biol., 148: 293-302.

VAN VLIET, B. N. \& WEST, N. H., 1992, Functional characteristics of arterial chemoreceptors in an amphibian (Bufo marinus). Respir. Physiol., 88: 113-127.

WEST, N. H. \& BURGGREN, W. W., 1984, Factors influencing pulmonary and cutaneous arterial blood flow in the toad, Bufo marinus. Am. J. Physiol., 247: R884R894.

WHITE, F. N., HICKS, J. W. \& ISHIMATSU, A., 1989, Relationship between respiratory state and intracardiac shunts in turtles. Am. J. Physiol., 256: R240-R247. 